\title{
ClOUd PlatForM FOR ROBOTARIUMS WITH WIRELESS COVERAGE NETWORKS, ENSURING SERVICE Robots With Parallel Simulation
}

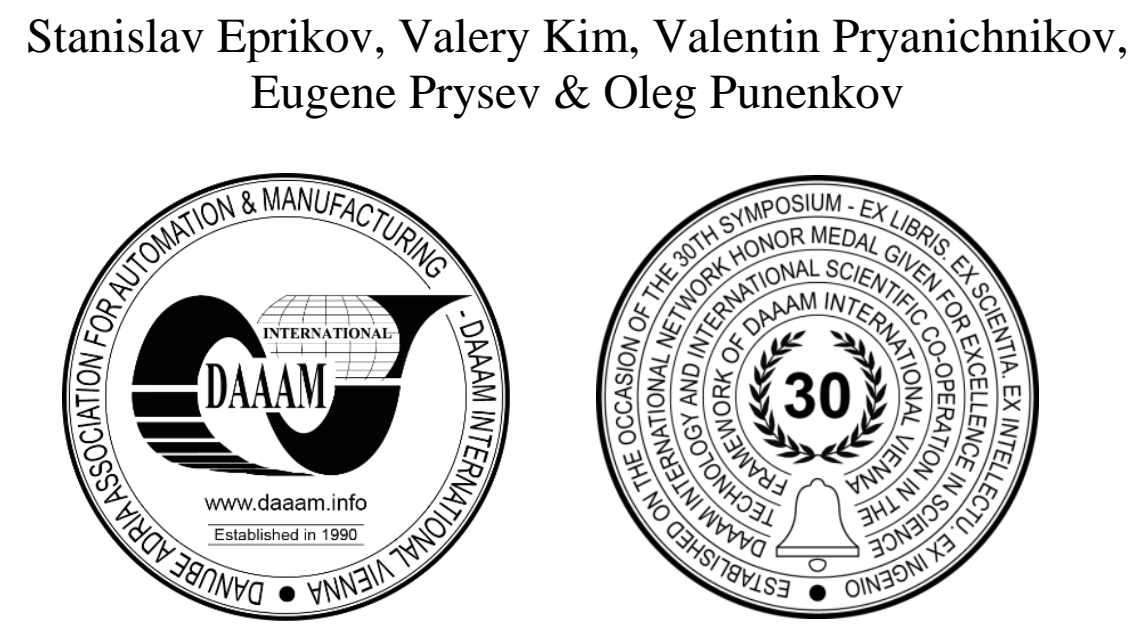

This Publication has to be referred as: Eprikov, S[tanislav]; Kim, V[alerii]; Pryanichnikov, V[alentin]; Prysev, E[vgeny] \& Punenkov, O[leg] (2019). Cloud Platform for Robotariums with Wireless Coverage Networks, Ensuring Service Robots with Parallel Simulation, Proceedings of the 30th DAAAM International Symposium, pp.1160-1165, B. Katalinic (Ed.), Published by DAAAM International, ISBN 978-3-902734-22-8, ISSN 1726-9679, Vienna, Austria DOI: $10.2507 / 30$ th.daaam.proceedings. 163

\begin{abstract}
This paper presents the results of the development and testing of a new software and information platform, that allows the user to provide unified access to the software environment for the control of various robots, including operation and remote reprogramming during their operation. This gives the following opportunities: reducing the cost of creating control programs; performing operational adjustments, including directly during the operation of robots; increase of efficiency of use of the developed technical means for improvement of educational processes for students of robotic and IT specialties, increase of coefficient of use of the educational equipment and decrease expense of parallelization of access to robots. It's also analyzed wireless coverage networks, ensuring control of service robots.
\end{abstract}

Keywords: building a network of robotariums, distributed control of mobile robots and their simulation models.

\section{Introduction}

When developing intelligent robots, one of the problems is the lack of effective software for creating group control systems. For example, the known software packages (ROS, MRS and others) do not provide special tools for the development of control of distributed mechatronic systems, especially in remote mode. They also have a common disadvantage - unreasonably high costs associated with the installation, updating and maintenance of equipment and the software environment running on it.

The application of the developed simulators, the actor model to the creation of an information technology platform for distributed software management, provided simultaneous access for several users to a group of mobile robots and their virtual models. For the first time within the framework of a single software platform, programming and control the parallel virtual models of mobile robots and their real prototypes are combined. The platform allows you the quickly and remotely reprogramming systems, significantly reduce the requirements for the level of qualification of specialists - software developers, providing the ability to scale each component of the system on physically distributed computers. Thus, the costs of adapting programs to specific tasks are significantly reduced, and the development of control systems and user interfaces is radically simplified. 
This approach was tested on mobile robots with different kinematic schemes, different types of microprocessor control and using sensors operating on different physical principles. Testing was carried out on the AMUR-307 robots, three Robotino robots and two small-sized mobile robots located in three laboratories-robotariums, as well as the simultaneous launch of 80 virtual simulators operating in real time. Experiments have confirmed all these advantages.

Further plans are to provide the expansion of the use of these approaches for educational and scientific experiments and the development of a network of robotariums created by IINET RSUH, the Chair of Sensor and control systems of MSTU "STANKIN" (basic Chair of KIAM RAS) together with the universities in Russia and Austria (Vienna Technical University), including by combining with the training network "Synergy" (project of concern "Festo"). It is also envisaged to further improve the characteristics embedded in the software platform of physical engines, testing the platform in the development of a production process control system with built-in logical control on the example of the industrial shop automation, implementing the concept of "Industry 4.0".

\section{Integrating software}

The development goal for the integrating software Roboplat was to make the cloud-based platform for distributed program control, providing simultaneous access of several users to a group of robots or mechatronic devices, as well as to their virtual models. Achieved features: 1. Interaction with robots using web-interface, 2. Working in a multi-user environment, 3. The possibility of reprogramming robots during their operation, 3. Simplicity and availability. 4. Crossplatform opportunity. Programming methods:

- Web-IDE

- PL: Typescript, Python, Scratch

- $\quad$ Auto-completion, hints, quick documentations, etc

- $\quad$ REST API (The OpenAPI)

- Unified API for virtual and real robots

Digital twins: Immediately switch between simulated and real robots. It will not require any changes in the code base. Roboplat integrates robarariums in different universities and companies for practical and educational purposes:

- RSUH

- MSTU "Stankin"

- Keldysh Institute of Applied Mathematics Russian Academy of sciences

- $\quad$ Festo AG \& Co. KG

Ease to use. Operation of the system takes place through the graphical interface of the web application, which allows you to see the status of individual equipment or the status of the system as a whole. It is possible to manually manage or create new custom rules through a web application in the scripting language TypeScript or in the simplified scratch visual language (for unskilled programmers). The correctness of the program can be checked in the built-in web application simulator. Thanks to the unified robotic software interface, the developed program is transparently transferred from a virtual to a real robots. The new hardware is automatically connected to the Roboplat shared network and is displayed as a part of the shared system. This can significantly reduce the time spent on the operation, configuration and integration of any new equipment.

Use of existing standards. The API specification uses the OpenAPI standard, which allows integration with many languages (36+) and integration with existing solutions. Roboplat can act as an intermediate solution between the user's system and the underlying third-party systems, which support systems such as ROS, etc.

\section{Wireless solutions and investigations}

While building a supervisor robot control, especially in extreme conditions, Wi-Fi wireless communications can be used. For example, we implemented multi-stream video transmission for the Brokk-type EMERCOM robots. However, in this case there are two problems - it is necessary to foresee, that the attenuation of the signal upon detection of coverage areas and the provision of switching control using the automatic return algorithm. In our work, a number of approaches to assessing the quality and quality of work were proposed. An experimental study of this parameter was carried out in robotized systems (IINET RGGU - Keldysh Institute of Applied Mathematics RAS), consisting of many rooms in which the control of mobile service robots Amur-307, Amur-105, educational robots Robotino and others.

To control the service robot, seamless roaming (handover) technology was implemented - providing Wi-Fi coverage, with access to several access points (clients), switching between zones, switching from one point to another without losing the signal [1]. When designing such a seamless wireless network, one of the most important conditions affecting the quality of the built network infrastructure is to determine the degree of attenuation of the wireless signal.

With the help of specialized software, a survey of parts of the building was conducted. Wall types and the actual scale of the plan were identified, and inconsistencies were corrected. DWL-3200AP provides the optimal location of access points to the most important signal transmission zones, taking into account the existing wired infrastructure. 
To reduce the level of interference, it was decided to use non-overlapping channels $(1,6,11)$ at $2.4 \mathrm{GHz}$. The implementation of the project to cover the premises with uninterrupted Wi-Fi signal coverage allowed not only to control the service robots, but also to create a public Wi-Fi infrastructure for visitors without the need for reconfiguration.

The first step in building a wireless network was to design it, taking into account the radio survey of all rooms. The plan of the rooms was drawn up, optimal places were chosen to install access points, taking into account the absorbing capabilities of walls, doors and other objects.

The project of a wireless Wi-Fi network should always include a radio inspection of the object at the design stage and prior to the installation of the equipment. Radio testing was carried out at the design stage to determine the configuration and optimal installation sites of equipment to ensure uninterrupted and high-quality network operation. There are two main types of radio survey:

1. Passive examination. It's conducted with a test access points, that are selected to build the network. The level of the received signal is measured, and the signals of all access points in the study zone are recorded in the $2.4 \mathrm{GHz}$ and 5 GHz bands.

2. Active examination. It implies the additional use of metering devices, that imitate a real subscriber device (mobile phone, tablet, laptop, barcode scanner) communicating with the access point. Measurement of real data: connection speed, packet loss, switching between points, diagnostics of client devices.

Using actual measurements at the site, a radio survey can be used to design a non-deployed Wi-Fi networks. This type of survey is called "predictive" or "virtual", since Wi-Fi characteristics are calculated for a virtual model of the environment created by the user. The process of creating and configuring a virtual environment, choosing the location of virtual access points (APs) and analyzing a simulated Wi-Fi network is usually called "RF-planning" [2].

Before the start of the survey, the robotarium plan and the plan of surrounding rooms, were received, on which the Wi-Fi network is tested. A study was conducted of the premises, the accuracy of the plan, the thickness and height of the walls were determined, as well as columns and fire doors were marked. The plan of the floor with schematic objects, is presented as a drawing with special designations (for example, as "BTI" plan). The designations used when creating floor plans of an object are called the graphical symbol (GS) and are governed by various State Standarts:

GOST 21.201-2011 Project documentation system for construction. Conventional graphic images of elements of buildings, structures and structures; GOST 21.205-93 SPDS. Symbols of elements of sanitary and technical systems.

Based on the information obtained during the analysis of these standards, a table of symbols used in terms of premises was created (Table 1).

\begin{tabular}{|c|c|c|}
\hline Name of the object & GS facility on the plan & Note \\
\hline Ladder (lower march) & क्षाH & $\begin{array}{l}\text { On the plans of the stairs the arrow indicates } \\
\text { the direction of raising the march. }\end{array}$ \\
\hline $\begin{array}{l}\text { Ladder (intermediate } \\
\text { marches) }\end{array}$ & & $\begin{array}{l}\text { On the plans of the stairs the arrow indicates } \\
\text { the direction of raising the march. }\end{array}$ \\
\hline $\begin{array}{l}\text { Ladder/stairway (upper } \\
\text { march) }\end{array}$ & 90 & $\begin{array}{l}\text { On the plans of the stairs the arrow indicates } \\
\text { the direction of raising the march. }\end{array}$ \\
\hline Column (support) & $E$ & \\
\hline Sink & & \\
\hline Window opening & 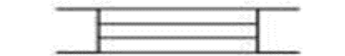 & \\
\hline Room number and its area & $\frac{3}{11,5}$ & \\
\hline
\end{tabular}

Table 1. Terms of premises, according with the Standards

When designing a seamless wireless network, it is worth to consider one of the most important conditions affecting the quality of the built network infrastructure - determining the degree of attenuation of the wireless signal. In order to take into account this important factor, a model of radio propagation in rooms is being developed. When building this model, the following factors should be considered: Signal interference with various electrical devices has a significant effect on signal propagation; Attenuation of a radio signal or its complete loss may occur as a result of passing through various obstacles or reflections from them. Obstacles include walls, beams, furniture, different types of doors, columns. Such objects, being on the path of radio signal propagation, partially / significantly (depending on the obstacle) absorb or reflect it, which leads to a deterioration in the signal quality. 
Each obstacle in the zone of propagation of a signal reduces its power. The more obstacles are there, the worse the signal becomes. It is also worth noting, that the Wi-Fi signal not only tries to bend around an obstacle, but also passes through it, which leads to additional reflection and absorption of a part of the original signal. Quality affects not only the number of walls located on the signal propagation path, but also their thickness. There are materials with a different signal absorption coefficient. For example, wood, plastic, ordinary glass, drywall refer to materials with low absorption. Tinted glass, water (large aquarium), bricks, plaster are materials with medium absorption. Materials with a high absorption coefficient, which have a strong negative effect on the signal, include metal (iron doors, aluminum and steel beams), concrete (inside which there is a reinforcing lattice), and ceramics. Indoors, mirrors can also cause radio signal interference (strongly reflect the signal) and tinted windows. The table below shows the loss of Wi-Fi signal efficiency, when passing through various environment. The values (not absolute, but approximate) are given for a wireless network operating in the $2.4 \mathrm{GHz}$ frequency band (Table 2).

\begin{tabular}{|c|c|c|}
\hline Obstacle & Additional loss, dB & Effective distance \\
\hline Open space & 0 & $100 \%$ \\
\hline Window without tinting (no metallized coating) & 3 & $70 \%$ \\
\hline Window tinted (metallized coating) & $5-8$ & $50 \%$ \\
\hline Wooden wall & 10 & $30 \%$ \\
\hline Interroom wall $(15.2 \mathrm{~cm})$ & $15-20$ & $15 \%$ \\
\hline Bearing wall $(30.5 \mathrm{~cm})$ & $20-25$ & $10 \%$ \\
\hline Concrete floor / ceiling & $15-25$ & $10-15 \%$ \\
\hline Monolithic reinforced concrete floor & $20-25$ & $10 \%$ \\
\hline
\end{tabular}

Table 2. Wi-Fi signal efficiency losses

Effective distance means how much the range of a Wi-Fi signal will decrease after passing the corresponding obstacle compared to open space [3]. To obtain a more extensive and accurate model of radio signal propagation, four main types of walls were identified that were used when working with the floor plan:

- Type 1 - thin partitions up to $10 \mathrm{~cm}$ thick (this type also includes windows inside the cabinets).

- Type 2 - interior walls with a thickness of $10 \mathrm{~cm}$ to $20 \mathrm{~cm}$, consisting of drywall.

- Type 3 - interior walls with a thickness of $10 \mathrm{~cm}$ to $20 \mathrm{~cm}$, consisting of concrete, sheathed with plasterboard.

- Type 4 - concrete and brick walls with a thickness of $20 \mathrm{~cm}$.

Considering these four views, the corresponding marks were made on the plans, showing where the type of walls is and their width. Formulated network requirements include: Number of users per point at least 10; Acceptable signal level, which is enough for both remote control of robots and Internet surfing (up to $-60 \mathrm{dBm}$ ); Seamless roaming.

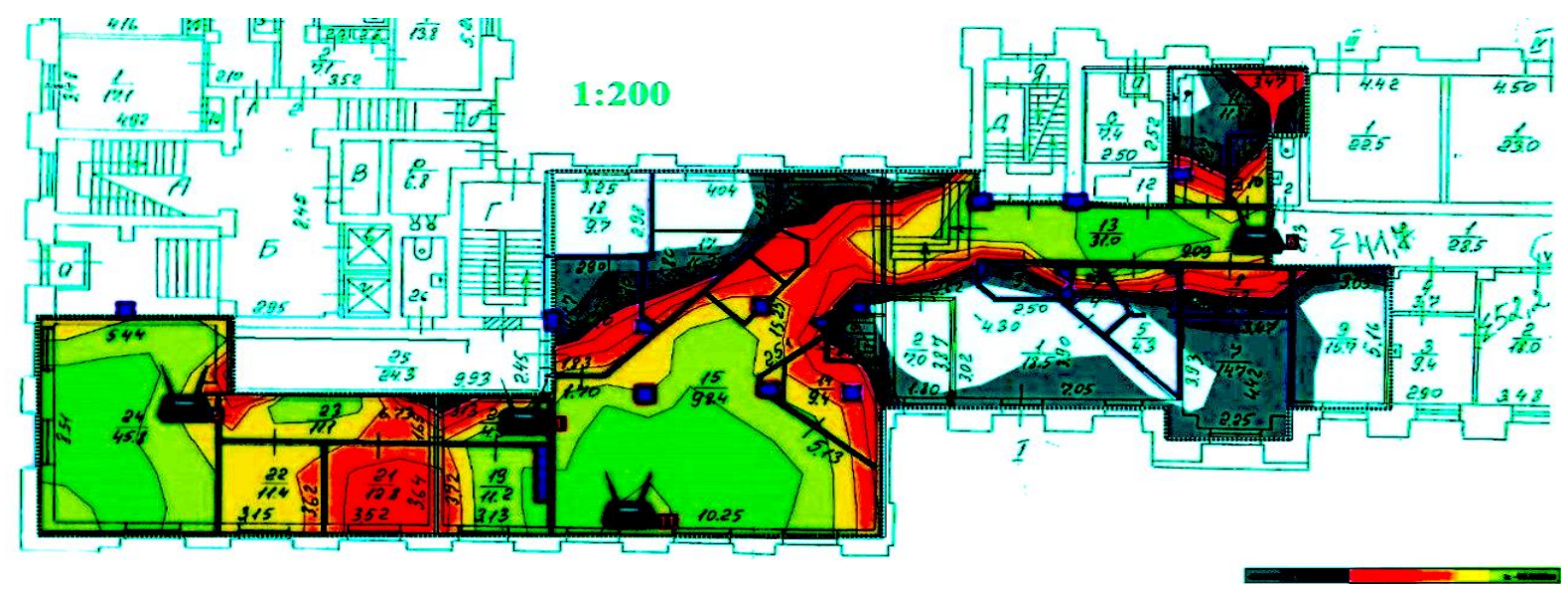

Fig. 1. The level of signal propagation using four APs .

In order to check the quality of the coating, a passive survey was conducted with test access points. Measurements were made of the received signal level in the study zone in the $2.4 \mathrm{GHz}$ band. The access points (AP) DWL-3200AP available at the customer participated in the modeling of the coverage. Based on the fact that there were 4 access points, their optimal location was determined in terms of covering the most important signal propagation zones (Fig. 1.). Also the existing wired infrastructure was taken into account to minimize the cost of installation work. To reduce the level of interference, it was decided to use non-overlapping channels $(1,6,11)$ at $2.4 \mathrm{GHz}$. Further analysis of the telecommunication equipment market was carried out in order to select the AP models most suitable for the tasks assigned and the following APs were considered: 
Ubiquiti UniFi AP (UAP), Ubiquiti UniFi AP LR (UAP-AC-LR), Ubiquiti UniFi AP Pro (UAP-AC -PRO), Ubiquiti UniFi AP AC Lite (UAP-AC-LITE). Table 3 shows the price range for these AP models, and Table 4 compares the characteristics of these Aps.

\begin{tabular}{|c|c|}
\hline AP equipment & Comparative cost of 1 pcs. \% \\
\hline Ubiquiti UniFi AP & 60 \\
\hline Ubiquiti UniFi AP LR & 100 \\
\hline Ubiquiti UniFi AP PRO & 125 \\
\hline Ubiquiti UniFi AP AC Lite & 80 \\
\hline
\end{tabular}

Table 3. Estimated cost of equipment on the market

\begin{tabular}{|c|c|c|c|c|}
\hline Parameters & UAP & UAP-AC-LITE & UAP-AC-PRO & UAP-AC-LR \\
\hline Wi-Fi standard & $\begin{array}{c}802.11 \mathrm{n} \\
(802.11 \mathrm{~b} / \mathrm{g} / \\
\mathrm{n})\end{array}$ & $\begin{array}{c}802.11 \mathrm{a} / \mathrm{b} / \mathrm{g} \\
/ \mathrm{n} / \mathrm{ac}\end{array}$ & $\begin{array}{c}802.11 \mathrm{a} / \mathrm{b} / \mathrm{g} / \mathrm{n} / \\
\mathrm{ac}\end{array}$ & $802.11 \mathrm{a} / \mathrm{b} / \mathrm{g} / \mathrm{n} / \mathrm{ac}$ \\
\hline $\begin{array}{c}\text { Frequency range Wi-Fi } \\
\text { devices }\end{array}$ & $2.4 \mathrm{GHz}$ & $2.4 / 5 \mathrm{GHz}$ & $2.4 / 5 \mathrm{GHz}$ & $2.4 / 5 \mathrm{GHz}$ \\
\hline $\begin{array}{c}\text { Max. Speed wireless } \\
\text { connections }\end{array}$ & $300 \mathrm{Mbit} / \mathrm{s}$ & $1167 \mathrm{Mbit} / \mathrm{s}$ & $1750 \mathrm{Mbit} / \mathrm{s}$ & $1300 \mathrm{Mbit} / \mathrm{s}$ \\
\hline $\begin{array}{c}\text { Simultaneous work in two } \\
\text { ranges }\end{array}$ & none & accessible & accessible & accessible \\
\hline Radius actions outpremises & no data & $122 \mathrm{~m}$ & no data & $183 \mathrm{~m}$ \\
\hline $\begin{array}{c}\text { Power transmitter } \\
\text { Speed ports }\end{array}$ & $20 \mathrm{dBm}$ & $20 \mathrm{dBm}$ & $22 \mathrm{dBm}$ & $24 \mathrm{dBm}(22 \mathrm{dBm}$ at \\
$5 \mathrm{GHz})$
\end{tabular}

Table 4. AP specifications

Let us consider the signal level by using various options. Hereinafter, the name of the pictures in brackets will indicate the signal level. For example, "AC LITE x $5(-60 \mathrm{dBm})$ " means that the signal level of $-60 \mathrm{dBm} \ldots-50 \mathrm{dBm}$ is highlighted in gray, the signal of the best level is colored in other color. Analyzing the data obtained, the customer was given the following recommendations on the choice of equipment:

- It does not make sense to consider UAP AP, since it does not know how to work in the $5 \mathrm{GHz}$ band, and in the future, if there is a need to connect, besides robots, also visitors, it is better to "unload" the $2.4 \mathrm{GHz}$ band for smooth work with robots. On the other hand, for 20 tr. one can take 5 of these access points.

- UAP AC LR and UAP AC PRO show almost identical results when using three points, and when using five. Therefore, it makes no sense to overpay for the PRO version.

- When choosing between UAP AC Lite and UAP AC LR, you should rely on the budget and the number of points. 


\section{Conclusion}

In this work, a survey was conducted of a rather large room of a robotarium at the Minot of the RSUH with the subsequent installation of access points and a passive radio survey that allowed testing the simulated coverage. Thus, confirmation was obtained of the effectiveness of the proposed method of building room models for designing sustainable supervisory control of a group of mobile robots for various purposes - service, for telemedicine, for surveying premises in extreme situations, including network deployment using the repeater robots themselves. Studies are also based on other works of our team - see [4-8]. Acknowledgment. The paper is partially supported by RFBR 19-07-00892.

\section{References}

[1] "Zyxel. Access points "[Electronic resource] - Access mode: https://kb.zyxel.ru/hc/ru/articles/115002584514Description of the modes of operation- wireless- point- access- Wi Fi, free. Reference date: 07/20/2018

[2] "TP-Link. Building a WLAN "[Electronic resource] - Access Mode: https://itnan.ru/post.php?c=1\&p=335674, free. Reference date: 07/20/2018

[3] "Zyxel. Wi-Fi "[Electronic resource] - Access mode: https://kb.zyxel.ru/hc/ru/articles/115002572093- Ratioattenuation ratios- Signal- Wi-Fi- through passage- through- various- environments, free. Reference date: $07 / 25 / 2018$

[4] Pryanichnikov V.E., Aryskin A.A., Eprikov S.R., Kirsanov K.B., Khelemendik R.V., Ksenzenko A.Ya., Prysev E.A., Travushkin A.S. (2017). Processing of Consumables, Proceedings of the 28th DAAAM International Symposium, pp. 1202-1207, B. Katalinic (Ed.), Published by DAAAM International, ISBN 978-3-902734-11 -2, ISSN 1726-9679, Vienna, Austria. DOI: 10.2507 / 28th.daaam.proceedings.167

[5] Ksenzenko A.Ya., Marzanov Yu.S., Prysev E.A., Pryanichnikov V.E., Chernyshev V.V. Prototyping of contactless data exchange and energy supply of a group of underwater satellite robots with a base station walking along the bottom. Extreme Robotics. // Collection of theses of the International Scientific and Technical Conference. - SPb: Gangut Publishing and Printing Complex, 2017.- 272 p., P. 268-269. ISBN 978-5-85875-522-7. (Extreme robotics. // Abstracts of the International Scientific and Technological Conference. - Saint-Petersburg: "Gangut", 2017. 272p.) URL: http://er.rtc.ru/images/docs/Sbornik_tezisov_ER_2017.pdf

[6] Pryanichnikov V.E., Ksenzenko A.Ya., Kuvshinov S.V., Poduraev Yu. V., Prysev E.A., Khelemendik R.V., Eprikov S. (2016). Intelligent robotics, Proceedings of the 27th DAAAM International Symposium, pp.0225-0229, B. Katalinic (Ed.), Published by DAAAM International, ISBN 978-3-902734-08-2, ISSN 1726 -9679, Vienna, Austria DOI: 10.2507 / 27th.daaam.proceedings.033

[7] Bogdanovich A.V., Kirsanov K.B., Pryanichnikov V.E., Helemendik R.V. Software and hardware components of intelligent service mobile robots / Information-measuring and control systems (Issue. Intelligent adaptive robots, V. 14, No. 1-2, 2019), M .: Radio Engineering, 2018, V. 16, No. 12 ,. p.33-39.

[8] Davydov D.V., Eprikov S.R., Kirsanov K.B., Pryanichnikov V.E. (2017). Service Robots Integrating Software and Remote Reprogramming, Proceedings of the 28th DAAAM International Symposium, pp.1234-1240, B. Katalinic (Ed.), Published by DAAAM International, ISBN 978-3-902734-11-2, ISSN 1726-9679, Vienna, Austria DOI: 10.2507/28th.daaam.proceedings. 172 . 